\title{
High-dose erythropoietin alters platelet reactivity and bleeding time in rodents in contrast to the neuroprotective variant carbamyl-erythropoietin (CEPO)
}

\author{
Agnete Kirkeby', Lars Torup', Louise Bochsen², Marianne Kjalke³, Kristin Abel ${ }^{3}$, Kim Theilgaard-Monch", \\ Pär I. Johansson ${ }^{2}$, Søren E. Bjørn ${ }^{3}$, Jens Gerwien ${ }^{3 *}$, Marcel Leist ${ }^{5 *}$ \\ 'H. Lundbeck A/S, Valby, Denmark; ${ }^{2}$ Department of Clinical Immunology, University Hospital of Copenhagen, Copenhagen, Denmark; \\ ${ }^{3}$ Novo Nordisk A/S, Måløv, Denmark; ${ }^{4}$ Department of Haematology, University Hospital of Copenhagen, Copenhagen, Denmark; ${ }^{5}$ Faculty \\ of Biology, University of Konstanz, Konstanz, Germany
}

\begin{abstract}
Summary
The haematopoietic hormone erythropoietin (EPO) has neuroprotective properties and is currently being explored for treatment of stroke and other neurological disorders. Short-term, high-dose treatment with EPO seems to improve neurological function of stroke patients but may be associated with increased thrombotic risk, whereas alternative non-erythropoietic neuroprotective derivatives of EPO, such as carbamylated EPO (CEPO), may be devoid of such side-effects. We investigated the effects of short-term, high-dose treatment with EPO and CEPO on platelet function and haemostasis in healthy mice and rats. Animals received three daily doses of EPO or CEPO $(50 \mu \mathrm{g} / \mathrm{kg})$, and blood was compared with respect to alterations in haematology and platelet reactivity. In rats, treatment with EPO increased the haematocrit to $>50 \%$ and the mean platelet volume by $37 \%$, while CEPO had no effect on these parameters. Platelets
\end{abstract}

from EPO-treated rats showed an increased sensitivity to thrombin receptor agonist peptides and elevated plasma levels of soluble P-selectin (sP-selectin) were found in treated mice. Further indicators of platelet hyperreactivity in EPO, but not CEPO-treated animals, were significantly increased aggregatory responses to collagen in whole blood and platelet-rich plasma (PRP). The increased platelet reactivity was paralleled by a decreased bleeding time after tail transection in rats. Samples from EPO-treated rats showed an attenuated response to ADP in whole blood aggregometry and thrombelastography (TEG) platelet mapping but not in apyrase-treated PRP, suggesting involvement of ADP receptor desensitization. These findings suggest that while EPO affects various aspects of platelet function, CEPO is devoid of such effects.

\section{Keywords}

ADP, collagen, P-selectin, MPV, stroke

\section{Introduction}

The cytokine erythropoietin (EPO) is the primary stimulator of erythropoiesis, and recombinant human EPO (rhEPO) is widely used in the treatment of anaemia (1). Additionally, EPO has attracted interest as a neuroprotective agent with therapeutic potential in diseases such as stroke, traumatic brain injury, schizophrenia and spinal cord injury (2). In small clinical trials, EPO seems to exert beneficial effects in stroke patients (3) as well as in schizophrenic patients (4). These studies suggest that EPO or EPO derivatives may be relevant for future treatment of patients suffering from a variety of central nervous system (CNS) disorders. However, treatment with EPO has been linked to an increased risk of thrombotic events, and EPO seems to affect various cardiovascular and haemostatic parameters unrelated to increases in haematocrit $(5,6)$. For instance, EPO treatment improves compromised platelet function in patients with renal failure independently of increases in haematocrit (7). In dogs, EPO induces a functional hyperreactivity of platelets, and potentiates thrombus development in a model of arteriovenous shunting $(8$, 9). EPO may also be pro-thrombotic in humans, both by increasing platelet reactivity and by causing an increase in systemic 
blood pressure through vasoconstriction $(5,10)$. These prothrombotic properties of EPO appear clinically relevant, since three trials evaluating EPO treatment in cancer patients were prematurely terminated due to increased thrombotic and cardiovascular events (6). In the stroke population, haemostatic side-effects of EPO are particularly undesirable, given the severe haemostatic disturbances in these patients (11).

The potential pro-thrombotic effects of EPO in treatment of anaemic patients have already been evaluated; however, for correction of anaemia, patients typically receive chronic treatment with low doses of EPO (i.e. 50-100 U $/ \mathrm{kg}=0.5-1 \mu \mathrm{g} / \mathrm{kg}$, three times weekly, [12]). In contrast, little is known about the adverse effects of short-term high-dose EPO treatment, which is relevant for neuroprotection. For example, beneficial effects in animal models of stroke are obtained with $1-3$ doses of $5-50 \mu \mathrm{g} / \mathrm{kg}$ EPO.

Non-erythropoietic derivatives of EPO, which do not bind to the classical EPO receptor, may have fewer unwanted haemostatic effects; however, this remains to be evaluated. The most studied EPO-derivative is carbamylated EPO (CEPO), which acts neuroprotectively in a variety of different animal models, such as cerebral ischemia $(13,14)$, autoimmune encephalomyelitis (13), spinal cord injury (13) and motor neuron degeneration (15). Given the potential use of EPO and CEPO as therapeutics for CNS indications, an evaluation of the thrombotic risks associated with high-dose, short-term EPO and CEPO treatment is warranted.

In this study, we tested the hypothesis that short-term highdose treatment with EPO affects haematological parameters including platelet function, whereas CEPO has no effect on these parameters. Thus, mice and rats were treated with EPO, CEPO or saline using a dosing protocol compatible with protocols tested in acute ischemic stroke studies. Haematological parameters and plasma levels of soluble P-selectin (sP-selectin) were determined as well as agonist-induced platelet reactivity investigated by flow cytometry, whole blood aggregometry, platelet-rich plasma (PRP) aggregometry and thrombelastography (TEG) platelet mapping. Plasma protein levels were analysed by Western blotting and the in vivo consequences of EPO and CEPO treatment were evaluated as bleeding time in the rat tail transection model.

\section{Materials and methods}

\section{Materials}

EPO from Dragon Pharmaceuticals (Vancouver, Canada) was used for all experiments. For studies on haematological parameters (Fig. 1), parallel experiments were run with Epoetin beta (NeoRecormon ${ }^{\circledR}$, F. Hoffmann-La Roche Ltd). CEPO was synthesized from EPO as described earlier (13). Identity and purity of the material as well as batch-identity was verified by amino group titration, digest with $\mathrm{LysC}$ and peptide fragment analysis by mass spectrometry as described elsewhere (13). The CEPO batch used in these experiments has been verified for neuroprotective activity in animal models (unpublished data). The mouse thrombin receptor PAR-3 (SFNGGP) and PAR-4 (GYPGKF) activating peptides were synthesized at Novo Nordisk (Denmark) using standard peptide chemistry.

\section{Animals and treatments}

All experimental procedures were carried out in accordance with the directives of the Danish National Committee on Animal Research Ethics and the European Communities Council Directive \#86/609 for care of laboratory animals. Animals were obtained from Charles River, Germany. Male NMRI mice weighing 25-30 g were dosed subcutaneously with a volume of $10 \mathrm{ml} / \mathrm{kg}$. Alternatively, Sprague-Dawley rats weighing 200-250 g were dosed with a volume of $1 \mathrm{ml} / \mathrm{kg}$. Animals were dosed once daily with EPO $(50 \mu \mathrm{g} / \mathrm{kg})$, CEPO $(50 \mu \mathrm{g} / \mathrm{kg})$ or saline $(0.9 \% \mathrm{NaCl})$ for $1-3$ days. For experiments with mice receiving doses lower than $50 \mu \mathrm{g} / \mathrm{kg}$, a protein-stabilising vehicle was used $(0.9 \% \mathrm{NaCl}+0.1 \%$ human serum albumin). All animals were euthanized after experiments.

\section{Analysis of haematological parameters}

Rats and mice were anaesthetized with isoflurane and blood was drawn from the vena cava with S-Monovette K-EDTA tubes (Sarstedt, Germany). Haematological parameters were analysed immediately on ADVIA ${ }^{\circledR} 120$ (Bayer, Germany) using multi species software 3.1 (Bayer).

\section{P-selectin flow cytometry}

Rats were anaesthetized with Avertin and blood was collected with S-Monovette citrate tubes by cardiac puncture. Citrated blood $(50 \mu \mathrm{l})$ was incubated with different concentrations of mouse thrombin receptor PAR-3 (SFNGGP) and PAR-4 (GYPGKF) agonist peptides for 5 minutes $(\mathrm{min})$ at $37^{\circ} \mathrm{C}$. Antibodies CD62-PE (Biotex, LY20, $3 \mu \mathrm{l}$ ) and CD61-FITC (BD $553346,4 \mu \mathrm{l}$ ) were added and incubated for $30 \mathrm{~min}$ at room temperature. Red blood cells (RBC) were lysed by incubating with $1 \mathrm{ml}$ red blood cell (RBC) lysing buffer (BD Bioscience FACS lysing solution, 349202, San Jose, CA, USA) for $10 \mathrm{~min}$ at room temperature before centrifugation for $5 \mathrm{~min}$ at $200 \mathrm{x} \mathrm{g}$. The pellet was washed with $2 \mathrm{ml}$ washing buffer ( $20 \mathrm{mM}$ Hepes $\mathrm{pH} 7.4$, $150 \mathrm{mM} \mathrm{NaCl}, 1 \mathrm{mg} / \mathrm{ml}$ bovine serum albumin [BSA]) and centrifuged for $5 \mathrm{~min}$ at $200 \mathrm{xg}$. FACSflow (BD Bioscience, $0.5 \mathrm{ml}$ ) was added to the pellet and samples were analysed on a FACSCanto flow cytometer (BD Bioscience). Forward and side scatter light channels and fluorescence channels were set on log. A gate was set on CD61 positive cells (all platelets), and \% of cells within this gate positive for P-selectin (CD62P) was determined. Single coloured activated platelets were used for compensation of overlapping fluorescence signals.

\section{sP-selectin ELISA}

Mice were anaesthetized with Avertin and blood was collected from the heart into S-Monovette tubes containing a mix of citrate, theophylline, adenosine, and dipyridamole (CTAD). Samples were immediately placed on ice and platelet-poor plasma was prepared by two rounds of centrifugation $(2,500 \mathrm{x} g$ for $20 \mathrm{~min}$ ). For each round the middle $1 / 3$ of the plasma phase was isolated for further procedure. Plasma samples were analysed by the mouse sP-selectin ELISA kit from R\&D systems (Minneapolis, MN, USA) at a 1:10 dilution.

\section{TEG platelet mapping}

The contribution of platelet-mediated response to clot strength was assessed by TEG measurements based on the TEG ${ }^{\circledR}$ Platelet 
Mapping assay kit and TEG analyser, series 5000, from Haemoscope Corp. (Skokie, IL, USA). Blood from Avertin-anaesthetized rats was collected in S-monovette lithium-heparin tubes by cardiac puncture. Whole heparinised blood $(360 \mu \mathrm{l})$ was added to a TEG cup containing Activator F (a snake venom directly converting fibrinogen to fibrin without activating the other coagulation enzymes) and ADP $(10 \mu \mathrm{M}$, final concentration) or collagen $(20 \mu \mathrm{g} / \mathrm{ml}$ final concentration, Collagenreagent Horm from Nycomed Pharma, Unterschleissheim, Germany). As parameter for the clot strength, the maximal amplitude (MA) was measured on the TEG Analyser. All samples were analysed 60-120 min after blood drawing.

\section{Whole blood aggregometry}

For aggregometry measurements, blood was sampled from Avertin-anaesthetized rats into S-Monovette citrate tubes by cardiac puncture. Samples of $300 \mu$ citrated whole blood were added to $300 \mu \mathrm{l} \mathrm{NaCl} / \mathrm{CaCl}_{2}$ solution (Dynabyte Medical, Munich, Germany) and preheated $3 \mathrm{~min}$ at $37^{\circ} \mathrm{C}$ in test cells (Multiplate, Dynabyte Medical). Collagen Horm (final concentration $2 \mu \mathrm{g} / \mathrm{ml}$ ) or ADP (final concentration 5 or $1 \mu \mathrm{M}$ ) in $20 \mu \mathrm{l}$ was added and aggregation measured for $6 \mathrm{~min}$ by impedance in a Multiplate instrument (Dynabyte Medical). Data are presented as area under the aggregation curve (AUC). All samples were analysed within $120 \mathrm{~min}$ after blood drawing.

\section{PRP aggregometry}

Heparinized blood $(3.6 \mathrm{U} / \mathrm{ml})$ was sampled from the inferior vena cava of EPO- or saline-treated rats under $\mathrm{CO}_{2}$-induced anaesthesia. PRP was prepared by $10 \mathrm{~min}$ centrifugation at $400 \mathrm{x}$ g. Before aggregation, PRP samples were incubated with apyrase $(1 \mathrm{mU} / \mathrm{ml}$, Sigma \#A6535) for $90 \mathrm{~min}$ at $37^{\circ} \mathrm{C}$ to remove any extracellular ADP present in the samples. Platelet aggregation was induced by addition of either $1 \mu \mathrm{M} \mathrm{ADP}$ or $3 \mu \mathrm{g} / \mathrm{ml}$ collagen, and the aggregatory response was measured over time by an optical aggregometer (300BD-5, Payton, USA) coupled to an XctionView Data Acquisition System (Singa Technology Corporation, Taiwan). Data are presented as peak aggregation and aggregation velocity determined as curve slopes during onset of the aggregatory response.

\section{Platelet preparation and immunoblotting}

Blood samples were collected from the hearts of Avertin-anaesthetized rats into S-Monovette CTAD tubes and were immediately kept on ice. For all further steps, platelets were kept on ice and centrifuged at $4^{\circ} \mathrm{C}$. PRP was prepared by three rounds of centrifugation at $200 \mathrm{xg}$ for 15,10 and $3 \mathrm{~min}$, respectively. After each centrifugation, the plasma and buffy coat were transferred to a new vial. Platelets were spun down at 2,000 $\mathrm{xg}$ for $5 \mathrm{~min}$ and resuspended in $400 \mu \mathrm{l}$ washing buffer $(129 \mathrm{mM} \mathrm{NaCl}, 13.6 \mathrm{mM}$ $\mathrm{Na}_{3}$-citrate, $11.1 \mathrm{mM}$ D-glucose, $\left.1.6 \mathrm{mM} \mathrm{KH}_{2} \mathrm{PO}_{4}\right)$. Remnants of red and white blood cells were removed by centrifugation at $200 \mathrm{x} g$ for 75 seconds (s), and platelets were washed twice before lysis on ice in $1 \%$ Nonidet P-40, $20 \mathrm{mM}$ Tris- $\mathrm{HCl} \mathrm{pH} 8$, $137 \mathrm{mM} \mathrm{NaCl}, 2 \mathrm{mM}$ EGTA, $10 \%$ glycerol with the following inhibitors: $1 \mathrm{mM} \mathrm{Na}_{3} \mathrm{VO}_{4}, 50 \mathrm{mM} \mathrm{NaF}, 10 \mathrm{mM} \mathrm{Na}$ - $\beta$-glycerophosphate, $1 \mathrm{mM}$ AEBSF and protease inhibitor mix Complete (Roche). Thirty $\mu \mathrm{g}$ of protein was loaded per well on $4-12 \%$ gradient Bis-Tris NuPAGE gels for SDS-PAGE (Invitrogen). For immunoblotting, the following antibodies were used: anti-P2 $\mathrm{Y}_{1}$ (Sigma, P6487), anti-P2Y 12 (Santa Cruz, sc-27152), anti-phospho-STAT3 (Cell Signaling, MA, U.S.A., \#9131), anti-MEK1/2 (Cell Signaling, \#9122), anti-GSK3 $\beta$ (Cell Signaling, \#9332), anti- $\beta$-actin (Sigma, A5441) and horseradish peroxidase-conjugated secondary antibodies (DAKO, Denmark). SeeBlue Plus2 prestained molecular weight markers from Invitrogen were included on the blots. Densitometric analyses of blots were performed using the AlphaEaseFC Software.

\section{Bleeding time in rats}

Rats were anaesthetised with Hypnorm/Dormicum and placed on heating pads throughout the experiment to maintain a body temperature of $37^{\circ} \mathrm{C}$. The tail was transected $5 \mathrm{~mm}$ from the tip with a single-use scalpel and the tail was immediately immersed into $37^{\circ} \mathrm{C}$ warm isotonic saline until termination of bleeding was noted. Termination of bleeding was defined as the time of complete stop of bleeding with no recurrence of bleeding within the next $60 \mathrm{~s}$. No animals exceeded a bleeding time of $30 \mathrm{~min}$. Cutoff tail tips were subsequently weighed to ensure that there was no difference in tail cutting between the groups. The treatment groups were blinded for the observer.

\section{Data presentation}

For haematological studies, no differences were observed between naïve animals and saline-treated controls, therefore only saline-treated controls are shown. Dragon EPO and Roche EPO behaved identically in haematological studies; data in Figure 1 are presented for Epoietin beta (Roche) only. Haemoglobin data completely paralleled the haematocrit data throughout all experiments and therefore is not shown. Data are presented as means \pm SEM and analysed by one-way ANOVA with Bonferroni's post-hoc test correction using Graph Pad Prism 4.02 software. P-values $<0.05$ were considered statistically significant. Asterisks and "ns" (non-significant) placed above the graph bars denote comparison to saline group.

\section{Results}

Alterations in blood parameters after short-term EPO treatment

Treatment of mice and rats once daily with EPO $(50 \mu \mathrm{g} / \mathrm{kg})$ for three consecutive days increased RBC count, reticulocyte count and mean platelet volume (MPV) when measured 48 hours (h) after the last dosing (Fig. 1). The increase in RBC and reticulocyte count corresponded to a rise in haematocrit from $40.9 \pm$ $0.5 \%$ (mean $\pm \mathrm{SEM}$ ) to $51.7 \pm 0.5 \%$ in mice, whereas the number of platelets remained unchanged in both mice and rats $(1,322 \pm$ 78 platelets/fl in mice and 1,285 \pm 195 platelets/fl in rats, mean $\pm \mathrm{SD}$, not shown). CEPO treatment did not alter any of the investigated blood parameters as compared to controls. Furthermore, rats and mice reacted identically to treatments on all parameters. To test whether acute dosing and handling or the presence of high concentrations of compounds in the samples had any effect on the haematological endpoints analysed, mice were treated with EPO, CEPO or saline for two days and blood was analysed immediately after the last dose. In this schedule, no differences were detected between the groups (not shown). 


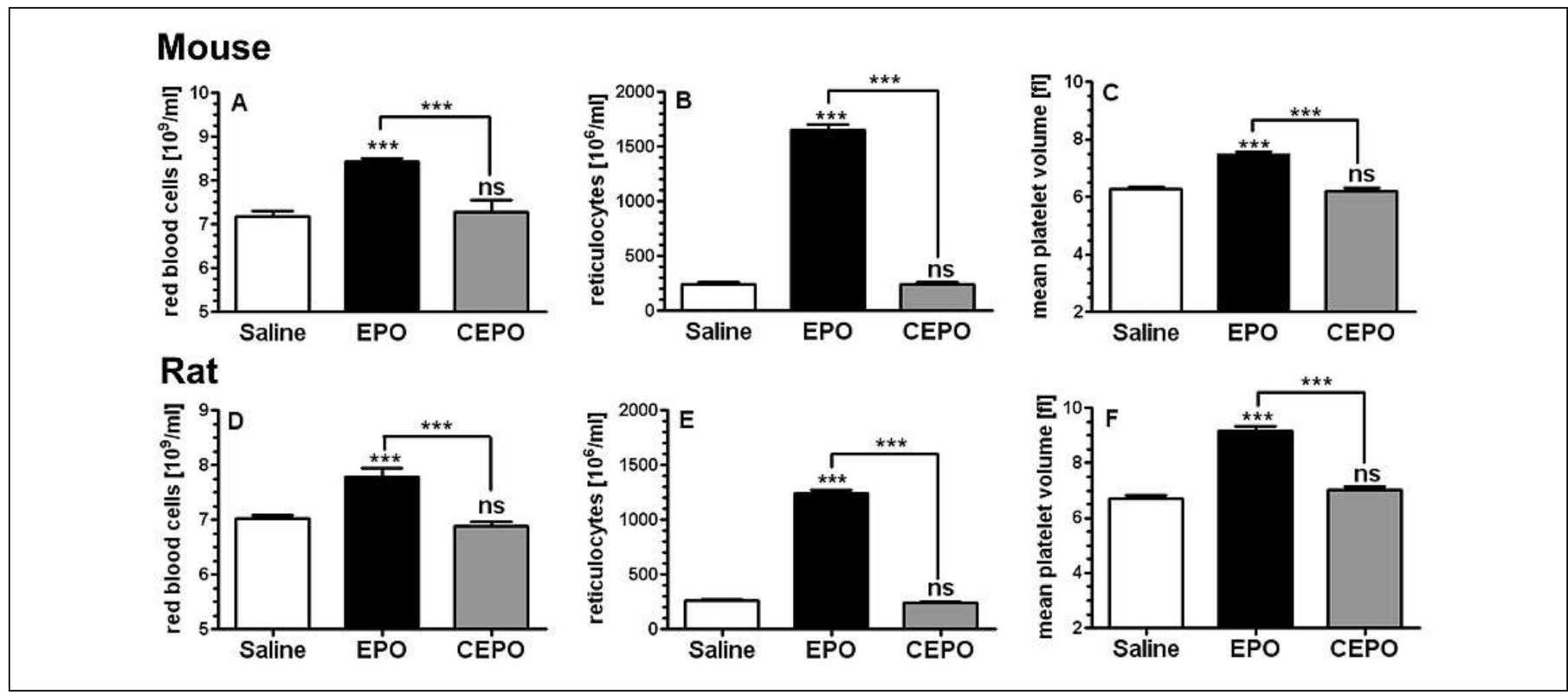

I: Haematological parameters from mice and rats treated with EPO or CEPO. Mice or rats were injected daily (s.c.) with either saline, EPO $(50 \mu \mathrm{g} / \mathrm{kg})$ or CEPO $(50 \mu \mathrm{g} / \mathrm{kg})$ for three consecutive days. Blood samples were collected $48 \mathrm{~h}$ after the last dose and haematological parameters were analysed. A-C) Haematological parameters from mice. D-F) Haematological parameters from rats. $(n=8)$. Data are presented as means \pm SEM. $\mathrm{fl}=$ femtoliter, $\mathrm{ns}=$ non significant, $* * *=\mathrm{p}<0.00 \mathrm{I}$.

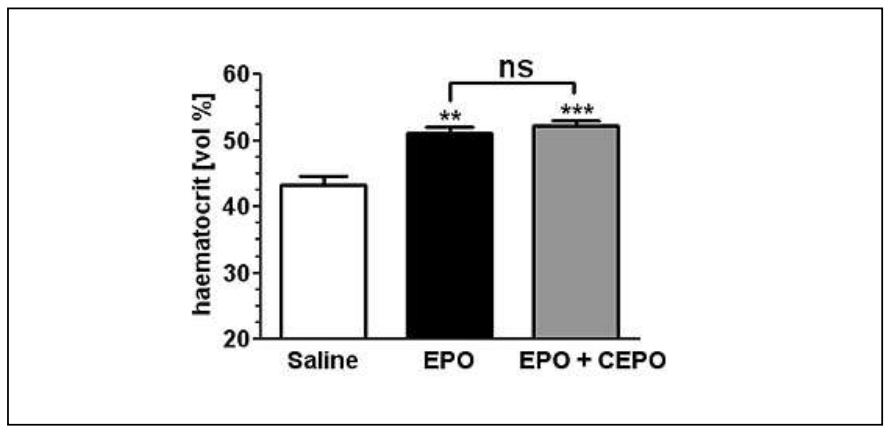

Figure 2: CEPO did not antagonise EPO-mediated activity in vivo. Three groups of mice were treated daily s.c. with either saline, EPO $(5 \mu \mathrm{g} / \mathrm{kg})$ alone or EPO $(5 \mu \mathrm{g} / \mathrm{kg})$ plus CEPO $(50 \mu \mathrm{g} / \mathrm{kg})$ for five days. Haematological parameters were measured on day $5(n=4-5)$. Data are presented as means \pm SEM. ns $=$ non significant, $* *=p<0.01$, $* * *=$ $p<0.001$ 


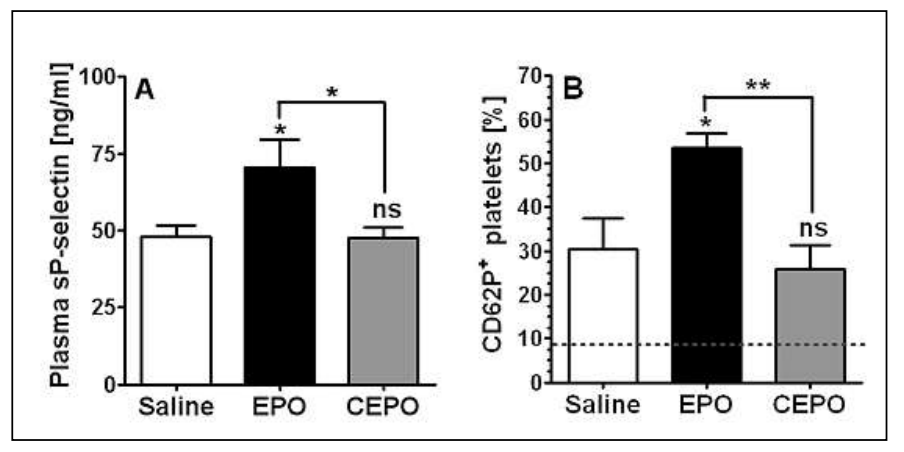

Figure 3: Thrombin receptor agonist-induced platelet P-selectin surface expression and SP-selectin plasma levels after treatment with EPO or CEPO. Three groups of animals were injected daily s.c. with saline, EPO $(50 \mu \mathrm{g} / \mathrm{kg})$ or CEPO $(50 \mu \mathrm{g} / \mathrm{kg})$ for three days and blood samples were collected $48 \mathrm{~h}$ after the last injection. A) Platelet-poor plasma from mice was analysed by ELISA for levels of sP-selectin $(n=9-10)$. B) Citrated blood samples from rats were treated with different concentrations of a mix of mouse thrombin receptor PAR-3 and PAR-4 agonist peptides and labelled with antibodies against CD6I (platelet marker) and CD62P (P-selectin, platelet activation marker) for flow cytometry analysis. Activation resulting from simulation with a submaximal concentration of agonist peptides ( $50 \mu \mathrm{M}$ of each) is shown $(n=6)$. Dotted line represents the baseline percentage of $\mathrm{CD}_{2} \mathrm{P}^{+}$platelets before agonist stimulation ( $8 \%$ for saline, $9 \%$ for EPO and CEPO). Data are presented as means \pm SEM. ns $=$ non significant, $*=p<0.05$, $* *=p<0.01$

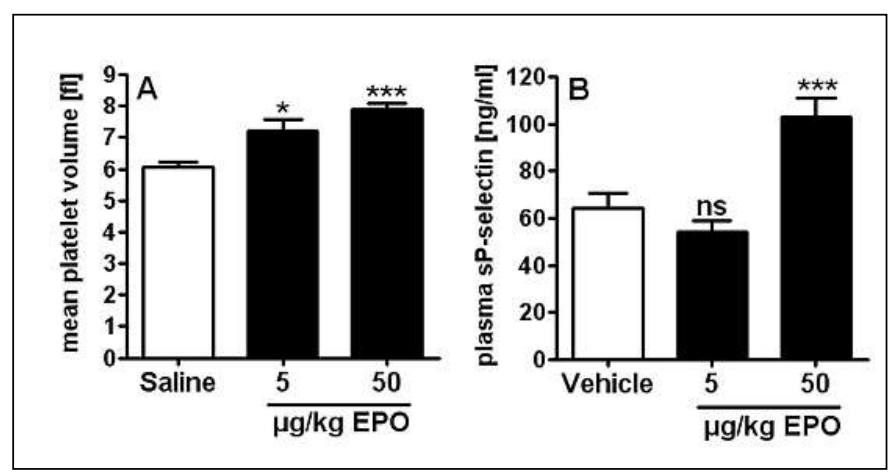

Figure 4: Dose-dependent effects of EPO on MPV and plasma sP-selectin. Three groups of animals were injected daily (s.c.) for three consecutive days with EPO (5 or $50 \mu \mathrm{g} / \mathrm{kg}$ ) dissolved in saline for rats, or vehicle (saline $+0.1 \%$ human serum albumin) for mice. Blood samples were collected $48 \mathrm{~h}$ after the last injection. A) Mean platelet volume measured in EDTA-stabilised blood from rats, $\mathrm{fl}=$ femtoliter $(\mathrm{n}=8)$. B) Levels of sP-selectin in platelet-poor plasma from mice, analysed by ELISA $(n=9-10)$. Data are presented as means \pm SEM. $n s=$ non significant, $*=p<0.05, * * *=p<0.001$.

\section{Altered whole blood aggregation responses to ADP and collagen after EPO treatment}

Additional functional platelet parameters were measured as agonist-induced platelet aggregation after short-term treatment with EPO or CEPO. Citrated blood from treated animals was subjected to whole blood aggregometry measurements after stimulation with the platelet agonists ADP or collagen. As before, rats received three daily doses of EPO, CEPO or saline, and blood was analysed $48 \mathrm{~h}$ after the last injection. EPO treatment enhanced aggregation in response to collagen, while CEPO had no effect compared to controls (Fig. 5A). In contrast, the response to ADP was significantly impaired in blood from EPOtreated rats (Fig. 5B). The effects of EPO on platelet function were further validated by examining blood from the same animals using TEG platelet mapping. TEG platelet mapping was performed by stimulating platelets in heparinized whole blood containing a fibrin network induced by a direct fibrinogen activator. Thus, this method measured the isolated contribution of platelet responses to clot strength. Using this method, the significantly decreased ADP response in EPO-treated animals was confirmed (Fig. 5C). To investigate whether EPO had any acute or direct effects on platelet reactivity, experiments were repeated with blood drawn at time points $4 \mathrm{~h}$ and $24 \mathrm{~h}$ after administration of a single dose of EPO. In these acute studies, EPO had no effect on ADP or collagen induced responses in TEG platelet mapping or whole blood aggregometry (not shown). CEPO did not influence blood responses in any of the aggregometry or TEG analyses performed. When analysing blood by standard TEG measurements with kaolin activation, no differences between the groups were detected (not shown).

\section{Altered PRP aggregation responses after EPO treatment}

The decreased ADP aggregatory response induced by EPO was surprising since our other data indicated a general platelet hyperreactivity after EPO administration. To address whether this phenomenon involved desensitization of the ADP receptors, we performed aggregation studies with ADP-depleted PRP in which platelets were allowed time to resensitize. ADP receptor desensitization occurs as a response to low level receptor activation by extracellular ADP, which may originate from platelet granule release or by haemolytic leakage of ADP from RBCs. Thus, to eliminate the interference of extracellular ADP in the aggregation response, we isolated PRP from saline- or EPO-treated rats and incubated the samples for $90 \mathrm{~min}$ at $37^{\circ} \mathrm{C}$ with a low concentration of apyrase ( $1 \mathrm{mU} / \mathrm{ml})$. Heparinized PRP was used for these experiments since apyrase is dependent on divalent cations and therefore does not work well in citrated samples. The concentration of apyrase was chosen to be sufficiently high to ensure complete depletion of adenine nucleotides from plasma (ATP + ADP in plasma is around $100 \mathrm{nM}[16]$ and $1 \mathrm{mU} / \mathrm{ml}$ apyrase degrades $1 \mu \mathrm{M} / \mathrm{min}$ of ATP and ADP), but too low to interfere significantly with ADP-induced aggregation. The $90 \mathrm{~min}$ incubation at $37^{\circ} \mathrm{C}$ was included to provide sufficient time for the platelet ADP-receptors to resensitize (17). When challenging the apyrase-treated PRP samples with ADP $(1 \mu \mathrm{M})$ we found no significant differences between saline and EPO-treated groups in peak aggregation (Fig. 6A) or area under the aggregation curve (not shown). However, after stimulation with collagen $(3 \mu \mathrm{g} / \mathrm{ml})$ we observed a significantly increased response in the EPO-treated group compared to controls, which was evident as a 95\% increase in peak aggregation (Fig. 6B) and a $350 \%$ increase in aggregation velocity (Fig. 6C).

\section{Alterations in platelet protein levels after EPO treatment}

In order to investigate whether EPO might alter basic platelet protein composition, we used Western blot analysis to examine 


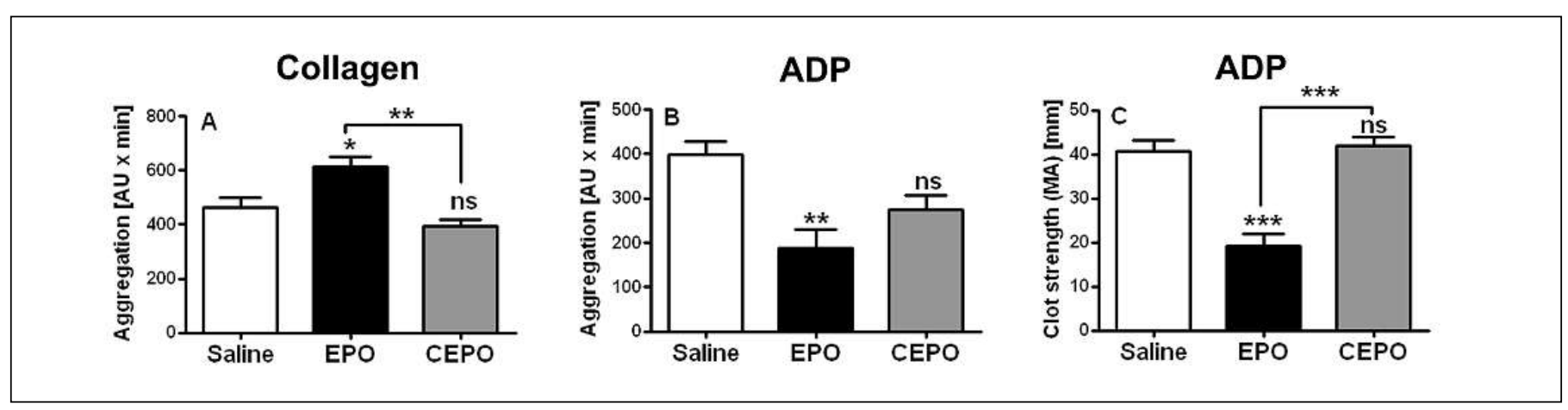

Figure 5: Agonist-induced whole blood aggregatory responses after treatment with EPO or CEPO. Three groups of rats were injected daily s.c. with saline, EPO $(50 \mu \mathrm{g} / \mathrm{kg})$ or CEPO $(50 \mu \mathrm{g} / \mathrm{kg})$ for three days and blood samples were collected $48 \mathrm{~h}$ after the last injection. A, B) Citrate-stabilised blood samples were stimulated with either $2 \mu \mathrm{g} / \mathrm{ml}$ collagen (A) or $5 \mu \mathrm{MADP}(\mathrm{B})$, and aggregation was measured by whole blood aggregometry. Graphs show values for area under the aggregation curve (AUC) resulting from integration of the aggregation re- sponse ( $A U=$ aggregation units) over the 6 min of the analysis. A baseline value of AUC without agonist was subtracted from all original values (baseline = $358 \pm 136 \mathrm{AU} \times \mathrm{min}$ ), $n=6-12$ for $A$ and $n=9-16$ for $B$. C: TEG platelet mapping of heparinized whole blood stimulated with $10 \mu \mathrm{M}$ ADP. Clot strength is determined by maximal amplitude (MA) on the TEG analyser $(n=9-12)$. Data are presented as means $\pm S E M . n s=$ non significant, $*=p<0.05, * *=p<0.01, * * *=p<0.001$. the levels of various platelet proteins in purified platelets from rats treated with three daily doses of EPO or CEPO as described before. Band density analysis revealed that levels of intracellular kinases MEK1/2 (MAP/ERK kinase) and GSK3 $\beta$ (glycogen synthase kinase-3 $\beta$ ) were up-regulated in platelets from EPOtreated animals, whereas levels of phosphorylated STAT3 (signal transducer and activator of transcription 3 ) were decreased (Fig. 7). When investigating levels of ERK1/2 (extracellular signalregulated kinase 1/2), Pyk2 (proline-rich tyrosine kinase 2), PI3K (phosphoinositide-3-kinase), Src, STAT5 or Akt (protein kinase B), no differences were found between the groups. We also probed the blots with antibodies against the ADP receptors $\mathrm{P} 2 \mathrm{Y}_{1}$ and $\mathrm{P} 2 \mathrm{Y}_{12}$, and observed significantly increased levels of proteins with the molecular weight of $66 \mathrm{kDa}$ for $\mathrm{P}_{2} \mathrm{Y}_{1}$ and $45 \mathrm{kDa}$ for $\mathrm{P}_{2} \mathrm{Y}_{12}$ following EPO treatment (Fig. 7). These bands correspond well to the sizes of transgenically expressed forms of the receptors $(18,19)$. However, we cannot exclude that the antibodies recognize other platelet proteins upregulated by EPO pre- treatment of the animals, as the commercially available antibodies lack absolute specificity for their cognate $\mathrm{P} 2 \mathrm{Y}$ receptors. GAPDH and $\beta$-actin were applied as loading controls, both yielding similar results.

\section{Bleeding time in rats affected by EPO but not CEPO}

As a model for testing the in-vivo consequences of EPO-mediated alterations in platelet function, bleeding time was measured in rats after transection of the tail tip. In this model, anti-platelet drugs such as aspirin and ADP receptor antagonists have been shown to prolong bleeding time, indicating that the model is sensitive to alterations in platelet function (20-22). Rats were dosed as previously described with EPO or CEPO (50 $\mu \mathrm{g} / \mathrm{kg}$ ) for three consecutive days, and bleeding time was measured $48 \mathrm{~h}$ after the last dose (Fig. 8). EPO treatment decreased bleeding time to $386 \pm 38 \mathrm{~s}$ compared to $694 \pm 82 \mathrm{~s}$ for saline-treated controls (mean $\pm \mathrm{SEM}, \mathrm{P}<0.05$ ). Bleeding time in CEPO-treated rats did not differ from control group $(650 \pm 126 \mathrm{~s})$.
Figure 6: Agonist-induced aggregation of apyrase-treated platelet-rich plasma (PRP) from rats. Two groups of rats were injected daily s.c. with saline or EPO $(50 \mu g / \mathrm{kg})$ for three days, and blood samples were collected $48 \mathrm{~h}$ after the last injection. PRP was prepared from heparinized blood and treated with apyrase before aggregation. Aggregation was induced by either I $\mu$ MADP (A) or 3 $\mu g / \mathrm{ml}$ collagen (B-D). A) Peak aggregation values above baseline for ADP-induced aggregation. B) Peak aggregation values above baseline for collagen-induced aggregation. C) Velocity for collagen-induced aggregation determined as the curve slope at initiation of aggregation. D) Representative aggregation curves for collagen-induced aggregation of PRP from EPO and saline-treated rats. $A U=$ aggregation units, $n=8$. Data are presented as means \pm SEM. ns $=$ non significant, $* * *=p<0.001$.

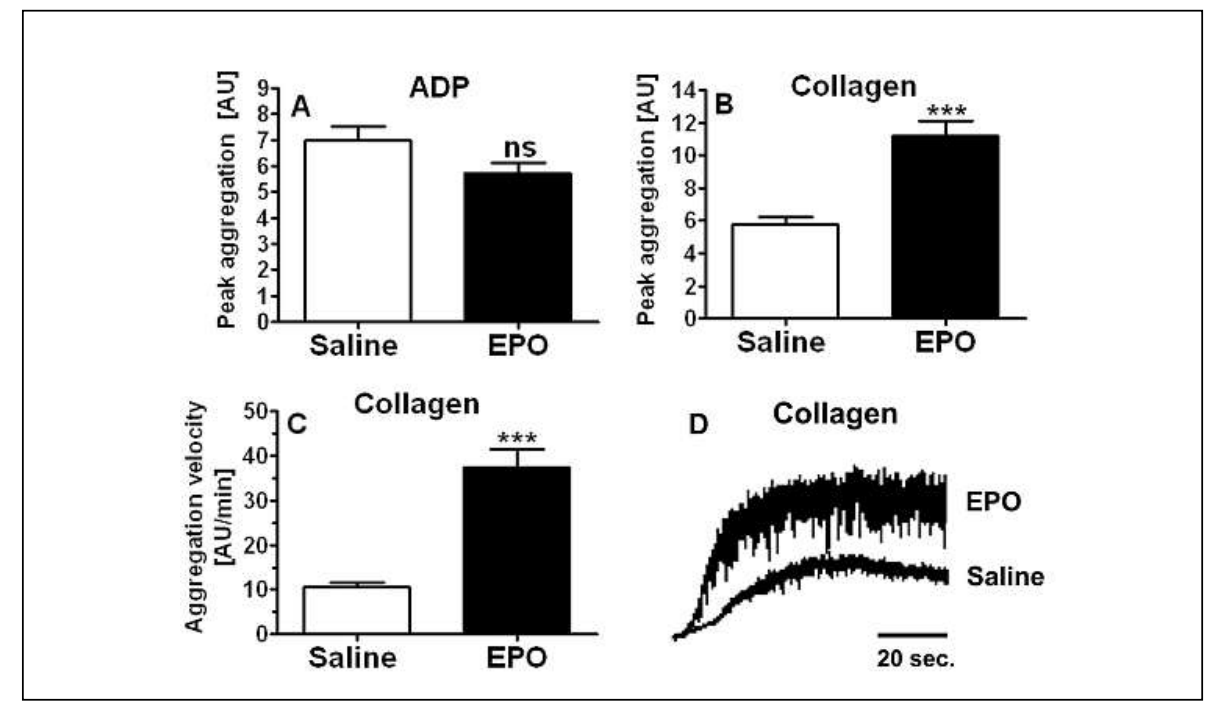




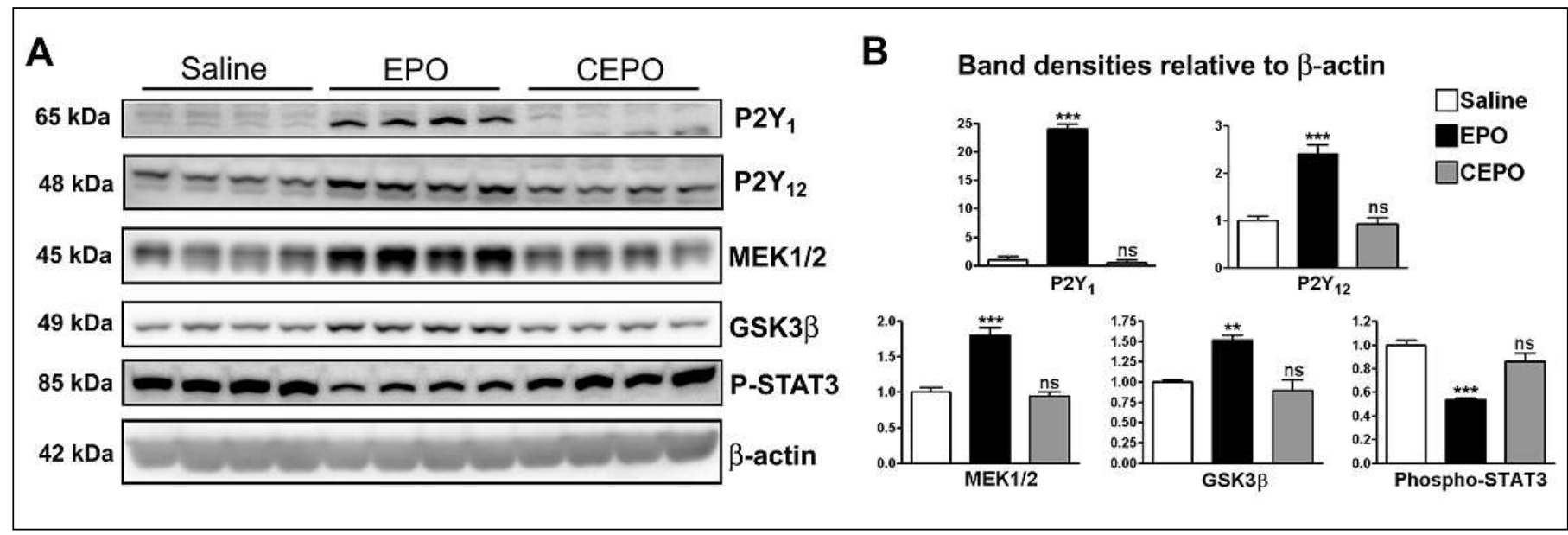

Figure 7: Western blot analysis of platelet proteins. Three groups of rats were injected daily s.c. with saline, EPO $(50 \mu \mathrm{g} / \mathrm{kg})$ or CEPO $(50 \mu \mathrm{g} / \mathrm{kg})$ for three days and platelets were purified from blood samples collected $48 \mathrm{~h}$ after the last injection. A) Lysates from purified platelets were subjected to Western blot analysis of $P 2 Y_{1}, P_{2} Y_{12}, M E K I / 2, G S K 3 \beta$ and phospho-STAT3. Each lane represents platelets from an individual

\section{Discussion}

The data presented here show that short-term, high-dose treatment with EPO significantly affected blood parameters and platelet reactivity, whereas such changes were absent in CEPOtreated animals. The platelet-altering effects of EPO seemed to be related to the high dose of $50 \mu \mathrm{g} / \mathrm{kg}$, since $5 \mu \mathrm{g} / \mathrm{kg}$ did not increase sP-selectin and only partially affected MPV. This dose-dependency explains why similar platelet profiles have not been found in previous studies with EPO in which lower doses have been tested. The $50 \mu \mathrm{g} / \mathrm{kg}$ dose is relevant for stroke therapy, as it is protective in most animal models of neuronal damage, and EPO at doses below $50 \mu \mathrm{g} / \mathrm{kg}$ is suboptimal for treatment of brain ischemia in the rat $(23,24)$. Furthermore, dosing of $50 \mu \mathrm{g} / \mathrm{kg}$ EPO in rodents is bioequivalent to the dose of about $5 \mu \mathrm{g} / \mathrm{kg}$ tested in humans in a small clinical stroke trial (3), taking into account the different weight-surface ratio, the 3-4 times extended half-life of recombinant human EPO in humans compared to rats and the lower affinity of human $\mathrm{EPO}$ for the rat $\mathrm{EPO}$ receptor $(13,25,26)$.

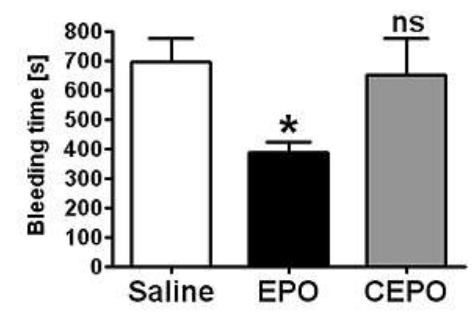

Figure 8: Bleeding time after tail transection in rats. Three groups of rats were injected daily s.c. with saline, EPO $(50 \mu \mathrm{g} / \mathrm{kg})$ or CEPO $(50 \mu \mathrm{g} / \mathrm{kg})$ for three days and tail transection was performed $48 \mathrm{~h}$ after the last injection. The time span until complete stop of bleeding was measured $(n=12)$. Data are presented as bleeding time in seconds (means \pm SEM). ns $=$ non significant, $*=p<0.05$. animal. Molecular weights (MW) of proteins estimated from the molecular weight marker are noted on the left. B) Densitometric analysis of bands in A. Y-axes denote band densities relative to $\beta$-actin with the saline group normalised to $I(n=4)$. Data are presented as means \pm SEM. ns $=$ non significant, ${ }^{* *}=p<0.01, * * *=p<0.001$.

Short-term EPO treatment with $50 \mu \mathrm{g} / \mathrm{kg}$ caused a dramatic rise in haematocrit in rodents, which was evident four days after the first dose, and the haematocrit reached critical levels above $50 \%$ (clinical bloodletting criterion). This potent effect on erythropoiesis is thus an issue in rodents after only three doses of EPO, and haematopoietic side effects may be even more prominent if EPO is to be used in long-term dosing schedules as might be relevant in chronic neurological disorders. In a recent clinical trial with non-anaemic schizophrenic patients, eight out of 20 EPO-treated patients required bleeding at least once during the three months experiment to reduce haematocrit, although patients received about $5 \mu \mathrm{g} / \mathrm{kg}$ EPO only once a week (4).

EPO furthermore caused an increase in MPV in rodents, which is consistent with findings in patients with chronic renal failure, but which has not earlier been found in healthy individuals (27). In humans, an increased MPV is correlated to a worsened outcome after cerebrovascular and cardiovascular events as well as to an increased risk of recurrent events of myocardial infarctions and stroke (28-30). MPV may thereby be a clinically relevant marker of risks associated with thrombotic events. In addition, EPO treatment increased plasma levels of sP-selectin, in accordance with findings in healthy human individuals (10). The soluble form of P-selectin is shed from platelets after P-selectin surface exposure, and it is itself a biologically active protein, which enhances clot formation and fibrin deposition (31). An increased plasma level of sP-selectin has been observed in acute stroke patients and is associated to various pro-thrombotic conditions, such as atrial fibrillation and atherosclerosis $(11,32$, $33)$.

Blood from animals pre-treated with EPO exhibited increased platelet sensitivity to thrombin receptor agonist peptides, as well as an increased aggregation response to collagen stimulation compared to platelets from saline-treated controls. In contrast, the platelet ADP-mediated response was markedly reduced by EPO treatment, showing a 50\% reduction in the TEG 
platelet mapping assay. The fact that the decreased aggregatory response to ADP was no longer observed in apyrase-treated PRP, which was allowed to rest in the absence of ADP, indicates that desensitization of platelet ADP receptors is a likely explanation for the phenomenon observed in whole blood. This seems even more likely in the light of our finding that the collagen response of PRP from EPO-treated animals was significantly enhanced, and the extent of enhancement appeared larger in apyrase-treated PRP than in whole blood aggregometry. A possible explanation for this could be that collagen-induced aggregation is a composite response reflecting both the isolated collagen-response and the reaction to secondarily released ADP (34). Thus, normalisation of the ADP response in apyrase-treated PRP may have revealed the true effect of EPO on the platelet collagen response. The desensitization of platelet ADP receptors could result from low-level granule release from circulating platelets leading to local increases in ADP levels which in turn activates and desensitizes platelet ADP receptors through internalization either in vivo or in vitro (35). Alternatively, the higher number of RBCs in EPO-treated animals may increase plasmatic ADP levels since adenosine phosphate compounds are released from RBCs both during normal physiologically responses in vivo and during haemolysis as may occur in vitro after blood sampling (36). However, the $50 \%$ decrease in ADP response observed in TEG platelet mapping suggests that the increase in $\mathrm{RBC}$ number is unlikely to be the sole contributor to desensitization.

The increased protein levels observed in Western blotting with antibodies against the ADP receptors $\mathrm{P} 2 \mathrm{Y}_{1}$ and $\mathrm{P} 2 \mathrm{Y}_{12}$ may indicate the presence of a counter-regulatory mechanism against ADP-receptor desensitization, possibly allowing platelets to increase ADP-receptor levels by translational control. Also proteins involved in intracellular pathways were regulated by EPO, including alterations in the levels of MEK $1 / 2$, GSK $3 \beta$ and phospho-STAT3, which are all involved in potentiation of platelet aggregation. The MAPK pathway involving MEK1/2 is responsible for production of thromboxane $\mathrm{A}_{2}$ after ADP stimulation (37) and STAT3 is involved in increasing platelet reactivity after thrombin stimulation (38). The role of GSK3 $\beta$ is largely unknown, but in human platelets, inhibition of GSK3 $\beta$ abrogates collagen-induced aggregation (39). The direct consequences of these modifications in platelet protein levels are yet unknown, but they indicate that EPO treatment has a clear effect on basic platelets composition. We suspect that alterations in platelet-protein composition may be partly responsible for changes in platelet reactivity. Elucidation of other proteins regulated by EPO (i.e. by proteomics approach) could help produce a more complete picture of the cause and consequence relationship between high-dose EPO treatment and platelet reactivity.

Although EPO treatment resulted in a complex aggregatory profile with increased responses to thrombin receptor agonist peptides and collagen accompanied by an attenuation of the ADP-response in whole blood, the bleeding time study confirmed that in-vivo clot formation was enhanced by EPO treatment. Few studies have investigated compounds which decrease bleed- ing time in normal animals, but increased bleeding time in the rat tail transection model correlates well with a decreased thrombus formation in in-vivo thrombosis models $(40,41)$.

Changes in MPV and platelet reactivity manifested only four days after the initial dose, and were not present at earlier time points tested. Furthermore, in-vitro stimulation of whole blood with high concentrations of EPO did not induce shedding of sPselectin, nor did it alter ADP- or collagen-induced aggregation (not shown). Therefore, it seems feasible that EPO does not exert direct effects on circulating platelets, but rather modulates platelets during synthesis and maturation in the bone marrow. Megakaryocytes possess high affinity binding sites for EPO and EPO affects these cells directly, causing an increase in megakaryocyte size and number both in vitro and in vivo $(42,43)$. This property of EPO is likely to explain our observations on MPV, since platelet size is determined at the time of synthesis and is thereby dependent on megakaryocyte volume (44). It has been hypothesized, based on studies in humans and dogs, that EPO treatment mediates an increased platelet turnover, thus involving an increased production of new and more reactive platelets as well as a premature loss of circulating platelets $(9,45,46)$. Additionally, EPO treatment causes a decrease in thrombin $\mathrm{EC}_{50}$ values for platelet activation, correlating to young platelets having a decreased thrombin $\mathrm{EC}_{50}$ compared to older platelets $(9,45,47)$. It is likely that the changes in platelet reactivity observed in this study, are a result of EPO-induced synthesis of new platelets exhibiting altered agonist responses, possibly due to alterations in expression of receptors and intracellular signalling proteins.

In summary, short-term treatment with EPO at doses optimal for neuroprotection caused significant alterations in platelet function and composition with in-vivo haemostatic consequences. In contrast, CEPO treatment had no effect on these parameters. Thus, CEPO seems to be devoid of any obvious haemostatic effects, thereby supporting a recent study showing that while EPO causes an acute rise in blood pressure in rats, CEPO, in contrast, does not (48). Animal studies have shown that EPO and EPO-derived compounds may have the potential to bring benefit for both embolic and haemorraghic stroke patients $(49,50)$. In both forms of CNS injury, it is important to treat haemostatic disturbances to avoid recurrent cerebrovascular events. The use of a stroke therapeutic, which alters elements of haemostatic function may interfere with the function of other anti- or pro-thrombotic drugs administered to patients, thereby complicating clinical management of these patients. Therefore, EPO derivatives such as CEPO, with neuroprotective potential and devoid of haemostatic effects, may be beneficial as novel therapeutics in the treatment of stroke.

\section{Acknowledgements}

The authors would like to thank Lone Odborg (Novo Nordisk A/S) and the animal facilities at $\mathrm{H}$. Lundbeck $\mathrm{A} / \mathrm{S}$ for excellent technical assistance, and Mads Dalsgaard for critical reading of the manuscript. Conflict of interest statement: A. Kirkeby and L. Torup are employees of H. Lundbeck A/S, which is developing EPO variants as CNS therapeutics. 


\section{References}

1. Fisher J W. Erythropoietin: physiologic and pharmacologic aspects. Proc Soc Exp Biol Med 1997; 216 . 358-369.

2. Hasselblatt M, Ehrenreich H, Siren AL. The brain erythropoietin system and its potential for therapeutic exploitation in brain disease. J Neurosurg Anesthesiol 2006; 18: 132-138

3. Ehrenreich H, Hasselblatt M, Dembowski C, et al Erythropoietin therapy for acute stroke is both safe and beneficial. Mol Med 2002; 8: 495-505.

4. Ehrenreich H, Hinze-Selch D, Stawicki S, et al. Improvement of cognitive functions in chronic schizophrenic patients by recombinant human erythropoietin. Mol Psychiatry 2007; 12: 206-220.

5. Vaziri ND. Cardiovascular effects of erythropoietin and anemia correction. Curr Opin Nephrol Hypertens 2001; 10: 633-637.

6. Peterson L. FDA oncologic drugs advisory committee (ODAC) meeting on the safety of erythropoietin in oncology. Trends Med 2004; 1-4.

7. Cases A, Escolar G, Reverter JC, et al. Recombinant human erythropoietin treatment improves platelet function in uremic patients. Kidney Int 1992; 42 : 668-672.

8. Wolf RF, Gilmore LS, Friese P, et al. Erythropoietin potentiates thrombus development in a canine arteriovenous shunt model. Thromb Haemost 1997; 77 1020-1024.

9. Wolf RF, Peng J, Friese P, et al. Erythropoietin administration increases production and reactivity of platelets in dogs. Thromb Haemost 1997; 78: 1505-1509.

10. Stohlawetz PJ, Dzirlo L, Hergovich N, et al. Effects of erythropoietin on platelet reactivity and thrombopoiesis in humans. Blood 2000; 95: 2983-2989.

11. Lip GY, Blann AD, Farooqi IS, et al. Sequential alterations in haemorheology, endothelial dysfunction, platelet activation and thrombogenesis in relation to prognosis following acute stroke: The West Birmingham Stroke Project. Blood Coagul Fibrinolysis 2002; 13: 339-347.

12. Clinical UniCare guidelines on erythropoietin Available at http://medpolicy.unicare.com/policies/ guidelines/DRUG/erythropoietin.html. Last accessed March 2007.

13. Leist M, Ghezzi P, Grasso G, et al. Derivatives of erythropoietin that are tissue protective but not erythropoietic. Science 2004; 305: 239-242.

14. Villa P, Van Beek J, Larsen AK, et al. Reduced functional deficits, neuroinflammation, and secondary tissue damage after treatment of stroke by nonerythropoietic erythropoietin derivatives. J Cereb Blood Flow Metab 2006; 27: 552-563.

15. Mennini T, De Paola M, Bigini P, et al. Nonhematopoietic erythropoietin derivatives prevent motoneuron degeneration in vitro and in vivo. Mol Med 2006; 12 : 153-160.

16. Gorman MW, Marble DR, Ogimoto K, et al Measurement of adenine nucleotides in plasma. Luminescence 2003; 18: 173-181.

17. Cauwenberghs S, Feijge MA, Hageman G, et al. Plasma ectonucleotidases prevent desensitization of purinergic receptors in stored platelets: importance for platelet activity during thrombus formation. Transfusion 2006; 46: 1018-1028.
18. Bodor ET, Waldo GL, Hooks SB, et al. Purification and functional reconstitution of the human P2Y12 receptor. Mol Pharmacol 2003; 64: 1210-1216.

19. Zhong X, Kriz R, Seehra J, et al. N-linked glycosylation of platelet P2Y12 ADP receptor is essential for signal transduction but not for ligand binding or cell surface expression. FEBS Lett 2004; 562: 111-117.

20. Dejana E, Villa S, de Gaetano G. Bleeding time in rats: a comparison of different experimental conditions. Thromb Haemost 1982; 48: 108-111.

21. Herbert JM, Bernat A, Samama M, et al. The antiaggregating and antithrombotic activity of ticlopidine is potentiated by aspirin in the rat. Thromb Haemost 1996; 76: 94-98.

22. Momi S, Pitchford SC, Alberti PF, et al. Nitroaspirin plus clopidogrel versus aspirin plus clopidogrel against platelet thromboembolism and intimal thickening in mice. Thromb Haemost 2005; 93: 535-543.

23. Wang Y, Zhang ZG, Rhodes K, et al. Post-ischemic treatment with erythropoietin or carbamylated erythropoietin reduces infarction and improves neurological outcome in a rat model of focal cerebral ischemia. $\mathrm{Br} \mathrm{J}$ Pharmacol 2007; 151: 1377-1384

24. Kellert BA, McPherson RJ, Juul SE. A comparison of high-dose recombinant erythropoietin treatment regimens in brain-injured neonatal rats. Pediatr Res 2007; 61: 451-455.

25. Spivak JL, Hogans BB. The in vivo metabolism of recombinant human erythropoietin in the rat. Blood 1989; 73: 90-99.

26. Macdougall IC, Roberts DE, Coles GA, et al. Clinical pharmacokinetics of epoetin (recombinant human erythropoietin). Clin Pharmacokinet 1991; 20: 99-113. 27. Sharpe PC, Desai ZR, Morris TC. Increase in mean platelet volume in patients with chronic renal failure treated with erythropoietin. J Clin Pathol 1994; 47: 159-161.

28. Martin JF, Bath PM, Burr ML. Influence of platelet size on outcome after myocardial infarction. Lancet 1991; 338: 1409-1411.

29. Bath $P$, Algert C, Chapman N, et al. Association of mean platelet volume with risk of stroke among 3134 individuals with history of cerebrovascular disease. Stroke 2004; 35: 622-626.

30. Greisenegger S, Endler G, Hsieh K, et al. Is elevated mean platelet volume associated with a worse outcome in patients with acute ischemic cerebrovascular events? Stroke 2004; 35: 1688-1691.

31. Andre P, Hartwell D, Hrachovinova I, et al. Pro-coagulant state resulting from high levels of soluble P-selectin in blood. Proc Natl Acad Sci USA 2000; 97 : 13835-13840.

32. Blann AD, Faragher EB, McCollum CN. Increased soluble P-selectin following myocardial infarction: a new marker for the progression of atherosclerosis. Blood Coagul Fibrinolysis 1997; 8: 383-390.

33. Li-Saw-Hee FL, Blann AD, Lip GY. A cross-sectional and diurnal study of thrombogenesis among patients with chronic atrial fibrillation. J Am Coll Cardiol 2000; 35: 1926-1931.

34. Toth $\mathrm{O}$, Calatzis A, Penz S, et al. Multiple electrode aggregometry: a new device to measure platelet aggregation in whole blood. Thromb Haemost 2006; 96: 781-788.

35. Baurand A, Eckly A, Hechler B, et al. Differential regulation and relocalization of the platelet $\mathrm{P} 2 \mathrm{Y}$ recep- tors after activation: a way to avoid loss of hemostatic properties? Mol Pharmacol 2005; 67: 721-733.

36. Wang L, Olivecrona G, Gotberg M, et al. ADP acting on $\mathrm{P} 2 \mathrm{Y} 13$ receptors is a negative feedback pathway for ATP release from human red blood cells. Circ Res 2005; 96: 189-196.

37. Shankar H, Garcia A, Prabhakar J, et al. P2Y12 receptor-mediated potentiation of thrombin-induced thromboxane A2 generation in platelets occurs through regulation of Erk1/2 activation. J Thromb Haemost 2006; 4: 638-647.

38. Vassilev AO, Lorenz DR, Tibbles HE, et al. Role of the leukemia-associated transcription factor STAT3 in platelet physiology. Leuk Lymphoma 2002; 43 1461-1467.

39. Barry FA, Graham GJ, Fry MJ, et al. Regulation of glycogen synthase kinase 3 in human platelets: a possible role in platelet function? FEBS Lett 2003; 553: 173-178.

40. Huang J, Wang S, Luo X, et al. Cinnamaldehyde reduction of platelet aggregation and thrombosis in rodents. Thromb Res 2007; 119: 337-342.

41. Martinichen-Herrero JC, Carbonero ER, Sassaki GL, et al. Anticoagulant and antithrombotic activities of a chemically sulfated galactoglucomannan obtained from the lichen Cladonia ibitipocae. Int J Biol Macromol 2005; 35: 97-102.

42. Berridge MV, Fraser JK, Carter JM, et al. Effects of recombinant human erythropoietin on megakaryocytes and on platelet production in the rat. Blood 1988; 72: 970-977.

43. Fraser JK, Tan AS, Lin FK, et al. Expression of specific high-affinity binding sites for erythropoietin on rat and mouse megakaryocytes. Exp Hematol 1989; 17: 10-16.

44. Martin JF, Trowbridge EA, Salmon GL, et al. The relationship between platelet and megakaryocyte volumes. Thromb Res 1982; 28: 447-459.

45. Haiden N, Cardona F, Schwindt J, et al. Changes in thrombopoiesis and platelet reactivity in extremely low birth weight infants undergoing erythropoietin therapy for treatment of anaemia of prematurity. Thromb Haemost 2005; 93: 118-123.

46. Tassies D, Reverter JC, Cases A, et al. Effect of recombinant human erythropoietin treatment on circulating reticulated platelets in uremic patients: association with early improvement in platelet function. Am J Hematol 1998; 59: 105-109.

47. Peng J, Friese P, Heilmann E, et al. Aged platelets have an impaired response to thrombin as quantitated by P-selectin expression. Blood 1994; 83: 161-166.

48. Coleman TR, Westenfelder C, Togel FE, et al. Cytoprotective doses of erythropoietin or carbamylated erythropoietin have markedly different procoagulant and vasoactive activities. Proc Natl Acad Sci USA 2006; 103: 5965-5970

49. Grasso G, Buemi M, Alafaci C, et al. Beneficial effects of systemic administration of recombinant human erythropoietin in rabbits subjected to subarachnoid hemorrhage. Proc Natl Acad Sci USA 2002; 99: 5627-5631

50. Lee ST, Chu K, Sinn DI, et al. Erythropoietin reduces perihematomal inflammation and cell death with eNOS and STAT3 activations in experimental intracerebral hemorrhage. J Neurochem 2006; 96: 1728-1739. 